\section{International Scientific Journal Theoretical \& Applied Science}

Vasila Karimbekovna Abdullaeva associate professor, candidate of medical sciences, head of department

Tashkent pediatric medical institute, Uzbekistan vasila.abdullaeva@tashpmi.uz

Year: $2016 \quad$ Issue: 1 Volume: 33

Published: $30.01 .2016 \quad$ http://T-Science.org

SECTION 20. Medicine.

\title{
CLINICAL-PSYCHOLOGICAL AND PATHOCHEMICAL MECHANISMS OF THE OPIOID ADDICTION OF PERSONS WITH COMORBID PATHOLOGY
}

\author{
Abstract: Investigated the influence of comorbid pathology at the clinical and psychosocial disorders in opioid \\ addiction, studied the intensity of systemic oxidative stress of patients, depending on the duration of disease. \\ Key words: opioid addiction, psychological status, oxidative stress. \\ Language: Russian \\ Citation: Abdullaeva VK (2016) CLINICAL-PSYCHOLOGICAL AND PATHOCHEMICAL \\ MECHANISMS OF THE OPIOID ADDICTION OF PERSONS WITH COMORBID PATHOLOGY. ISJ \\ Theoretical \& Applied Science, 01 (33): 58-63. \\ Soi: http://s-o-i.org/1.1/TAS-01-33-12 Doi: crossef http://dx.doi.org/10.15863/TAS.2016.01.33.12

\section{КЛИНИКО-ПСИХОЛОГИЧЕСКИЕ И ПАТОХИМИЧЕСКИЕ МЕХАНИЗМЫ СИНДРОМА ЗАВИСИМОСТИ ОТ ОПИОИДОВ У ЛИЦ С КОМОРБИДНОЙ ПАТОЛОГИЕЙ}

Аннотация: Исследовано влияние коморбидной патологии на клинические и сочииальнопсихологические нарушения при зависимости от опиоидов, изучена интенсивность системного окислительного стресса у больных в зависимости от длительности наркотизации.

Ключевые слова: зависимость от опиоидов, психологический статус, окислительный стресс.

Проблема наркомании является в настоящее время «одной из острейших глобальных проблем, представляющих собой угрозу здоровью населения, экономике, социальной сфере, правопорядку во многих странах мира» [9, с.115]. Вопросы клиники и течения синдрома зависимости от опиоидов до настоящего времени остаются актуальными, малоизученными и вызывающими научно-исследовательский интерес. Огромное разнообразие и изменчивость клинических проявлений при наркоманиях заставляет врачей в своей повседневной практике сталкиваться с необходимостью решения все более сложных диагностических и лечебных задач [10, с.98]. Вместе с этим, закономерным является и вопрос о стержневом синдроме заболевания - патологическом влечении к наркотику, которое занимает место симптомов «первого ранга», патогномоничного признака [1, c.11]. Медико-социальная реабилитация больных с зависимостью от опиоидов является одним из приоритетных направлений наркологии [3, с.38]. Именно на этапах медико-социальной реабилитации достигается восстановление физического, психического и духовного здоровья наркологических больных, их личностного и социального статуса, а длительные ремиссии наркологического заболевания формируются, прежде всего, благодаря соблюдению адекватных принципов построения лечебнореабилитационных программ. Целями лечения являются соблюдение отказа от приема психоактивного вещества, к которому сформировалась зависимость; уменьшение тяжести симптомов заболевания, улучшение общего состояния здоровья и социального функционирования, исключение или снижение риска развития рецидива [7, с.212].

Выявлены неблагоприятные факторы, которые определяют быстроту формирования медицинских и социальных последствий наркоманий. В исследованиях определено значение наследственной предрасположенности к зависимости от психоактивных веществ, клинико-биологических предикторов, социальных, в том числе влияния родительской 
семьи $[11$, с.182; 14, с.8]. Преморбидные личностные особенности в формировании и развитии зависимости от психоактивных веществ по данным некоторых авторов встречаются в $86 \%$ случаев [1, с.12]. Личностные расстройства у больных наркоманией установлены от $28 \%$ до 65 $90 \%$ случаев [12, с.1312].

Основные формы соматических осложнений у лиц, употребляющих наркотики, включают гепатотоксический, кардиотоксический, энцефалотоксический, нефротоксический и смешанный типы органопатологии, из них поражения гепатобилиарной системы (гепатит токсического или инфекционно-токсического генеза) развивается в 73,6\% случаев [11, с.180; 14 c.10]. Печень является главным органоммишенью у больных наркоманией из-за непосредственно токсического влияния героина, инфицирования вирусами гепатитов $\mathrm{B}, \mathrm{C}$ или их сочетания, а также дополнительного влияния алкоголизма, нарушений питания, действия токсических примесей, содержащихся в наркотиках кустарного производства $[13$, с.438; 15, c.402].

Несмотря на значительное количество работ, посвященных роли клиникопсихопатологических и личностных расстройств, соматической отягощенности в генезе заболевания, вопрос взаимосвязи и прогностического значения клиникодинамических и патохимических особенностей зависимости от опиоидов еще недостаточно изучен.

Целью исследования явилось изучение клинико-психологических и патохимических особенностей героиновой наркомании у лиц с коморбидной патологией.

Материал и методы исследования. В исследование было включено 324 больных мужского пола в возрасте от 18 до 55 лет, имеющих клинически очерченную зависимость от наркотиков опийной группы (МКБ 10- F11.2). Для проведения анализа значимости клиникодинамических факторов в развитии зависимости от опиоидов обследованные больные разделены нами на 2 группы. Основная исследуемая группа больных, зависимых от опиоидов, в сочетании с соматическими расстройствами, составила 173 человека. Группа сравнения $\mathrm{n}=151$ представлена больными с зависимостью от опиоидов без соматического заболевания. Группа больных с коморбидной патологией отбиралась по принципу максимального представительства в общей исследуемой группе зависимых от опиоидов. Данные по основным соматическим расстройствам в основной группе исследования: наличие вирусных гепатитов В и С. Диагноз гепатита В и С выставлялся после индикации соответствующих серологических маркеров в лаборатории.

исследования

Основными

были

методами

психопатологический, клиническая беседа, интервьюирование и анкетирование, а также стандартизированные психологические методики: шкала патологического влечения к наркотику $[3, \quad$ c.40], сокращенный многофакторный опросник для исследования личности (СМОЛ), методика определения уровня субъективного контроля (УСК) Дж. Роттера (адаптация Е.Ф.Бажина, 1998). Для определения интенсивности процессов перекисного окисления липидов (ПОЛ) было проведено определение уровня малонового диальдегида (МДА) в сыворотке крови [6, с.67], активности каталазы в крови [5, с.82], определение среднемолекулярных пептидов (СМП) [4, с.20].

Результаты исследования и их обсуждение. В ходе исследования выявлено, что наиболее раннее начало эпизодического употребления психоактивных веществ (13-14 лет) отмечено в основной группе $(40,8 \%)$, что достоверно отличается от группы сравнения $(19,8 \%) \quad(\mathrm{p}<0,05) . \quad$ Нами осуществлен сравнительный анализ особенностей структуры патологического влечения к наркотику у больных основной группы и группы сравнения. Патологическое влечение к наркотику, представленное идеаторным компонентом, в основной группе имело место в $100 \%$ случаев, что превышало аналогичный показатель группы сравнения $(91,4 \%, \mathrm{p}<0,05)$. При этом весьма значительное превышение определялось и по аффективным расстройствам $(85,9 \%$ и $77,2 \%)$ и соматовегетативному компоненту (79,9\% и 54,9\% основной группы и группы сравнения соответственно). Распределение частоты патологического влечения к наркотику показало превышение доли случаев со средней степенью тяжести влечения в основной группе и группе сравнения - $60,9 \%$ и $87,7 \%$ соответственно. Необходимо отметить, что в основной группе больных патологическое влечение к наркотику тяжелой степени выраженности было достоверно выше, чем в группе сравнения (36,9\% против $8,6 \%, \quad \mathrm{p}<0,005)$. Значимые различия между рассматриваемыми группами фиксируются по тяжести синдрома патологического влечения, максимально представленного в основной группе. Таким образом, клинико-динамические механизмы патологического влечения при героиновой наркомании являются причинным фактором развивающихся нарушений адаптации. Фактор коморбидности оказывает неоднозначное влияние на степень выраженности основных симптомов патологического влечения к наркотику, что связано с биологической и стрессогенной патопластической спецификой анализируемых видов коморбидной патологии. 
Изменение формы опьянения - последний во времени симптом из входящих в синдром измененной реактивности и развивается на фоне уже существующих наркоманических синдромов $[7,27]$. В основной группе типичная форма наркотического опьянения с преобладанием эйфории представлена сравнительно реже $(11,4 \%)$. Также сравнительно более редко представлена форма наркотического опьянения с преобладанием апатии $(7,6 \%)$ и замкнутости $(7,6 \%)$. И сравнительно более часто - измененные формы наркотического опьянения с преобладанием тоски $(25,5 \%)$, плаксивости $(15,2 \%)$, дисфорических расстройств настроения $(17,4 \%)$, а также - суицидальных тенденций демонстративного характера $(7,6 \%)$. В группе сравнения отмечалось существенное преобладание измененных форм наркотического опьянения с эйфорией $(25,9 \%)$, апатией $(13,6 \%)$ и тоской $(19,8 \%)$. Полученные результаты свидетельствуют, что анализируемые виды коморбидной патологии изменяют форму наркотического опьянения по типу дополнительной экзогенно-органической вредности, а также - по типу дополнительного психотравмирующего фактора.

В результате анализа профилей СМОЛ зависимые от опиоидов с коморбидной патологией проявляли высокий уровень аутичности, эмоциональной напряженности и астенизации в сочетании с существенно большей импульсивностью и чертами несдержанности, ухудшающие социальную адаптацию. Выявлены общие личностные особенности: смешанный тип реагирования с выраженными чертами шизоидности, снижением эмоционального фона, уровня побуждений и общительности, обособленно личностная позиция, склонность к раздумьям превалирующей над чувствами и деятельной активностью. Больные группы сравнения в большей степени склонны к проявлениям стеничности, протестным явлениям, нонконформизму, импульсивности. Анализ результатов УСК показал, что в основной группе отмечается низкий уровень субъективного контроля в областях общей интернальности, интернальности неудач и производственных отношений, в группе сравнения - средний уровень субъективного контроля в областях общей интернальности, интернальности неудач и производственных отношений. Зависимым от опиоидов основной группы характерны черты экстернальности. Употребление наркотика сформировало у этих больных чувство беспомощности, потребность в заботе, опеке окружающих. Особую значимость приобретают необходимость оберегания своей социальной позиции. Зависимые от опиоидов ранимы, чувствительны, зависимы от мнения других, с низкой адаптивностью и страхом перед трудностями. Имеет место мотивация избегания неудачи при достаточно ригидных установках. Их дезадаптация может быть связана со стрессовыми ситуациями и отражать проявления временной адаптивной реакции. Она может свидетельствовать о неустойчивой личностной интеграции и отражать патологические изменения личности. Группе сравнения характерны средние значения УСК, что в жизненных ситуациях может проявляться сравнительной удовлетворенностью качеством своей жизни. Адаптация больных к новым условиям средняя. Отсутствует тенденция к доминированию. В личностно значимых ситуациях возможно принятие этими личностями ответственности на себя, но при появлении фрустрирующей ситуации возможен уход от решения проблем. В целом, они руководствуются внутренними побуждениями, проявляя интернальность или экстернальность в зависимости от ситуации. Все эти варианты объединяет определенный тип дезадаптации, индивидуально-личностный стиль переживаний и определенные методы защиты. Таким образом, совокупность психологических показателей и наличие коморбидной патологии определяет зависимость между соматическим расстройством и уровнем субъективного контроля.

В ходе проведенного исследования нами изучена интенсивность системного окислительного стресса у больных с зависимостью от опиоидов. Анализ полученных данных позволил установить, что интенсивность генерации активных форм кислорода (АФК) в крови у обследованных пациентов изменяется в широких пределах и возрастает с увеличением длительности наркотизации, присоединения поражения печени в виде токсикоинфекционного гепатита. Так, у больных с зависимостью от опиоидов без соматической отягощенности имеется умеренно выраженная эндотоксемия (увеличение СМП в 3 раза) и окислительный стресс (увеличение МДА в 2,6 раза) на фоне снижения активности каталазы в 1,5 раза по сравнению с контролем, тогда как у больных с зависимостью от опиоидов с коморбидной патологией снижение активности каталазы наблюдалось в 3,5 раза, а уровень МДА и СМП превышали контроль в 5,0 и 5,5 раза соответственно (табл.1). 
Интенсивность генерации активных форм кислорода в крови обследованных пациентов.

\begin{tabular}{|c|c|c|c|}
\hline Группа больных & $\begin{array}{c}\text { МДА } \\
\text { нмоль /мг белка* мин }\end{array}$ & $\begin{array}{c}\text { СМП } \\
\text { Е/мг белка }\end{array}$ & $\begin{array}{c}\text { Каталаза, } \\
\text { ммоль } \mathrm{H}_{2} \mathrm{O}_{2} / \text { млн. эрит } \\
{ }_{\text {м мин }}\end{array}$ \\
\hline Контрольная группа & $0,51 \pm 0,09$ & $0,021 \pm 0,001$ & $40,1 \pm 1,7$ \\
\hline Основная группа & $1,31 \pm 0,10^{*}$ & $0,063 \pm 0,009^{*}$ & $26,9 \pm 1,1 *$ \\
\hline Группа сравнения & $2,61 \pm 0,13 * * *$ & $0,109 \pm 0,012 * * *$ & $11,6 \pm 0,9^{* * *}$ \\
\hline
\end{tabular}

Примечание. * - достоверно по отночению $\kappa$ контролю, $P<0,05$; ** достоверно относительно длительности наркотизации до 1 года.

Таким образом, при хронической интоксикации опиатами развивается системный окислительный стресс с активным вовлечением печени. Полученные нами результаты свидетельствуют о влиянии на уровень окислительного стресса в крови при опийной наркомании длительности наркотизации и сопутствующего ей поражения печени. Поражение печени скудно проявляется клинически, однако о функциональном поражении гепатоцитов свидетельствует системный оксилительный стресс, который развивается при исчерпании антиоксидантной мощности организма и депо антиоксидантов в печени.

Обсуждая полученные данные, отметим, что липопероксидация и окислительная деградация белков под действием АФК вносит вклад в функционирование опиоидных рецепторов и реализацию эффекта опиоидов. Как показали наши наблюдения, окислительный стресс в крови сопровождается эндогенной интоксикацией, т.к. взаимодействие АФК с молекулами белковой и липидной природы приводит к образованию низкомолекулярных продуктов ( $\mathrm{Mr}<5000$ Да), обладающих токсическим действием - СМП.

Одним из важнейших неблагоприятных негативных последствий хронической наркотизации опиатами является физическая зависимость, проявляющаяся специфическими поведенческими нарушениями, и как ее следствие - развитие абстинентного синдрома. На течение абстинентного синдрома существенно влияют характерные для опийной наркомании соматические расстройства - гепатотоксичность и иммунодефицит.

Так, согласно нашим данным, в период воздержания от наркотиков у больных опийной наркоманией были выявлены аффективные, идеаторные, поведенческие и вегетативные компоненты патологического влечения, актуализация которых отличалась вариабельностью, пароксизмальностью или волнообразностью, а характер был прямо противоположен действию опийных наркотиков. Отметим, что психопатологические компоненты опережали соматовегетативные проявления. У лиц с постабстинентным состоянием, длившемся более 3 недель, параметр окислительного стресса - уровень МДА был достоверно выше $(\mathrm{p}<0,05)$, чем у лиц с продолжительностью абстинентного

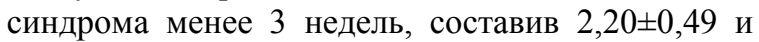
$1,4 \pm 0,18$ нмоль/мг белка* мин соответственно.

Таким образом, особенностью биохимических нарушений гомеостаза у больных с зависимостью от опиоидов является развитие усиления генерации АФК в крови, следствием чего является развитие эндотоксемии в виду накопления продуктов деградации макромолекул белковой и липидной природы. Вероятно, столь разительное увеличение изученных параметров явилось следствием недостаточности защитной системы, включающей как ферменты с антипероксидным и антирадикальным механизмом действия, так и резерв жиро- и водорастворимых биоантиоксидантов в печени $[11,15]$. Эндогенная интоксикация и окислительный стресс связаны и с поражением печени, они влияют на течение абстинентного синдрома, т.к. у больных с высоким уровнем МДА и СМП абстиненция протекала длительнее и тяжелее.

Необходимо отметить, что наши результаты исследования состояния антиоксидантной системы у больных с зависимостью от опиоидов свидетельствуют об угнетении ферментативного звена антиоксидантной защиты и необходимости включения препаратов, обладающих антиоксидантными свойствами при лечении данной категории больных. Купирование 
окислительного стресса необходимо для нормализации мембрано-деструктивных процессов в организме, в первую очередь, в мозге и печени, что обеспечит адекватность (а не извращенность) метаболизма в микросомальной окислительной системе препаратов, используемых в лечении - антидепрессантов, нейролептиков и др., оптимизирует постнаркотическую детоксикацию, что позволит укоротить течение абстинентного синдрома и снизить его тяжесть.

\section{Выводы.}

1. Наличие коморбидной патологии способствует развитию средней степени и тяжелых форм патологического влечения к наркотику $(\mathrm{p}<0,05), \quad$ изменяет характер наркотического опьянения с преобладанием тоски $(25,5 \%)$ и дисфорических расстройств $(17,4 \%)$, а также суицидальных тенденций демонстративного характера $(7,6 \%)$.

2. Совокупность клинико-психологических показателей и наличие коморбидной патологии определяет зависимость между соматическим расстройством, личностным профилем и уровнем субъективного контроля у зависимых от опиоидов. Зависимые от опиоидов с коморбидной соматической патологией по сравнению с группой больных без коморбидной патологии обнаруживают низкий уровень субъективного контроля, высокий уровень аутичности, эмоциональной напряженности в сочетании с большей импульсивностью и чертами несдержанности, ухудшающие социальную адаптацию.

3. Интенсивность генерации активных форм кислорода в крови у зависимых от опиоидов изменяется в широких пределах и возрастает с увеличением длительности наркотизации и сопутствующим поражением печени, проявляясь увеличением малонового диальдегида, среднемолекулярных пептидов и угнетением активности каталазы в 5,0; 5,5 и 3,5 раза относительно контроля соответственно $(\mathrm{p}<0,05)$, что диктует необходимость включения препаратов, обладающих антиоксидантными свойствами при лечении данной категории больных.

\section{References:}

1. Anokhina IP (2007) Boilogicheskie mehanizmy predraspolojennosti $\mathrm{k}$ zavisimosti ot psihoaktivnyh veshestv. // I.P.Anokhina / Psihiatriya i psihofarmakoterapiya. 2007. - T. 9, №1, pp. 10-14.

2. Bohan NA (2008) Neyrobiologicheskie problemy izucheniya addiktivnyh rasstroystv (obzor regionalnyh issledovaniy) // N.A.Bohan / Sibirskiy vestnik psihiatrii i narkologii. 2008. № 1. - pp. 59-63.

3. Vinnikova MA (2010) Profilaktika retsidiva pri opiatnoy zavisimosti: obshie podhody k terapii // M.A.Vinnikova / Voprosy narkologii. 2010. №6. - pp. 36-48.

4. Gabrielyan NI, Levitskiy ER, Dmitriyev AA, et al. (1985) Skriningovyi metod opredeleniya "srednih molekul" v biologicheskih jidkostyah: Metodicheskiye recomendatsii. Moscow, 1985.$26 \mathrm{p}$.

5. Zubkova SM, Bah AN (1976) Kolichestvennoye opredeleniye aktivnosti katalazy krovi. // S.M.Zubkova, A.N.Bah. / Rukovodstvo k laboratornym zanyatiyam po biologicheskoy himii. - Moscow: Meditsina, 1976. - pp.81-83.
6. Stalnaya ID, Garishvili TG (1977) Metod opredeleniya malonovogo dialdegida $\mathrm{s}$ pomoshyu tiobarbiturovoy kisloty/ // I.D.Stalnaya, T.G.Garishvili / Sovremennye metody v biohimii. - Moscow: Meditsina, 1977. - pp. 66-68.

7. Dudko TN (2011) Sovremennye podhody k reabilitatsii bolnyh s zavisimostyu ot PAV. // Klinicheskiye i organizatsionnye voprosy narkologii. / Pod red. E.A.Koshkinoy. M.: Genius Media, 2011. - 580 p.

8. Semke VY (2006) Personologicheskiy analiz v kontekste sistematiki addiktivnyh sostoyaniy/ / V.Ya.Semke, N.A.Bohan, A.R.Mandel/ // Narkologiya. - 2006. - №1.- pp.60-65.

9. Sivolap YP (2005) Zloupotrebleniye opioidami i opioidnaya zavisimost. / Yu.P.Sivolap, V.A.Savchenkov. Moscow: Meditsina, 2005. $304 \mathrm{p}$.

10. Pyatnitskaya IN (2008) Obshaya i chastnaya narkologiya, rukovodstvo dlya vrachey Moscow: Meditsina, 2008. - 640 p.

11. Rohlina ML (2001) Narkomanii. Meditsinskiye I sotsialniye posledstviya. Lecheniye. / M.L.Rohlina, A.A.Kozlov. Moscow: Anaharsis, 2001. - 208 p. 


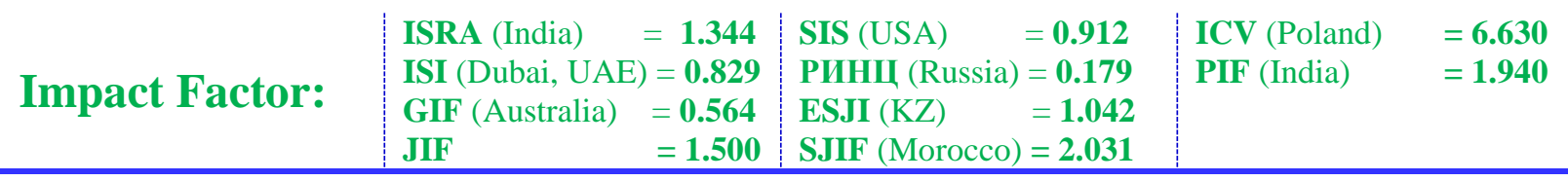

12. Bowden-Jones OB (2005) Prevalence of personality disorder in a substance misuse treatment population and associated comorbidity / O.B. Bowden-Jones, M. Iqbal, P. Tyrer et al. // Addiction. 2005. - Vol. 99, №1. pp. 1306-1314.

13. Kaplan IY (2000) Somatic and Neurological Complications in Drug Addicts / I.Y. Kaplan, A.A. Kozlov // J. European Psychiatry. 2000 (Oct.). - Vol. 15, № 2. -pp. 436-439.
14. Khalsa JH (2005) Medical Consequences of Drug Abuse and Cooccurring Infections: Research at the National Institute on Drug Abuse / J.H. Khalsa, G. Treisman, E. McCanceKatz, E. Tedaldi // Subst. Abus. 2008. - Vol. 29, № 3. - pp. 5-16.

15. Koob GF (2006) The neurobiology of addiction / G.F. Koob, M. Le Moal; Eds. G.F. Koob. San Diego: Academic press, 2006. - 490 p. 